\title{
Methods and Advances in the Forensic Analysis of Contaminated Rivers
}

\author{
Jerry Miller ${ }^{1, *}$ \\ ${ }^{1}$ Department of Geosciences and Natural Resources, Western Carolina University, Cullowhee-USA
}

\begin{abstract}
Trace metals and metalloids are a common and persistent form of riverine (river) contamination and are derived from a wide variety of sources, including mining and milling operations, industrial activities, urban runoff, agricultural chemicals, and atmospheric pollution, among a host of others. Documentation of trace metal sources and dispersal pathways in riverine ecosystems is essential to mitigate their potentially harmful effects to human and ecosystem health and is often required from a legal (environmental forensic) perspective to assess liability for the costs of remediation. Unfortunately, documenting the sources and source contributions of trace metals in rivers has proven difficult, time-intensive, and costly. Herein, a fourcomponent, interdisciplinary framework is proposed to efficiently identify the sources and source contributions of trace metals in alluvial sediments where multiple natural and/or anthropogenic sources exist. The components include (1) the analysis of the river's alluvial stratigraphic architecture and geomorphic history, (2) the temporal correlation of geochemically characterized alluvial deposits to potential anthropogenic trace metal sources, (3) the analysis of the spatial variations in selected geochemical parameters, and (4) the use of geochemical and/or isotopic tracers to quantitatively estimate the contributions of trace metals from the defined natural and anthropogenic sources. The four components are not intended to be exhaustive; the framework may require modification following multiple lines of evidence approach, in which additional methods and data are added to the investigation until there is confidence that all trace metal sources and their contributions have been effectively defined.
\end{abstract}

Keywords: Environmental Forensics; Trace Metals; Contaminated Rivers.

\section{Introduction}

Trace metals and metalloids (herein referred to collectively as trace metals) are one of the most common and persistent contaminants in riverine ecosystems[1-6]. In rivers characterized by "normal" $\mathrm{Eh}$ and $\mathrm{pH}$ conditions, trace metals are primarily sorbed onto sediments, particularly fine-grained, chemically reactive sediments, composed of clay minerals, iron $(\mathrm{Fe})$ and manganese $(\mathrm{Mn})$ oxides and hydroxides, and organic matter. As a result, $90 \%$ or more of the total trace metal load is typically transported with particulates by physical processes [7,8], and incorporated into channel bed, floodplain, and other types of alluvial (river) deposits $[9,10]$. These alluvial deposits, then, contain a record of the spatial and temporal variations in the quantity of trace metal inputs into, and transported through, the river system, and their analysis can provide insights into the degree to which anthropogenic activities including mining, agriculture, urbanization, and industry, among others, have contaminated the aquatic environment. Moreover, the river (riverine) sediments can be used to determine the source of trace metals within the river.

The determination of trace metal sources has become one of the most important components of river cleanup for two primary reasons. First, the success of a remediation program depends on identifying where the contaminants are coming from, and then reducing or eliminating their input into the aquatic environment. In fact, the improvements in water quality in many countries since the 1970s have primarily been related to the implementation of environmental regulations that restrict the input of contaminants to water bodies from identified sources, particularly those related to industrial or mining activities. Second, the determination of trace metal sources is often driven by the polluter-pays-principal in which the polluter is required by law to pay for the cleanup of the river such that it is returned a close approximation of its previous condition.

In the U.S., for example, the Comprehensive Environmental Compensation, Response and Liability Act (CERCLA), frequently referred to as the Superfund Program, was enacted in 1980 at the federal level to address the most contaminated sites across the country. State governments have also enacted hazardous waste site remediation programs largely patterned after CERCLA. The developed legislation at both the federal and state levels allows for the allocation of liability to potentially responsible parties (PRPs). These PRPs may include single or multiple person(s) and entity(ies) such as current and past site owners or operators, generators of chemical wastes, and those involved in or responsible for the transport of wastes between sites [11].

\footnotetext{
$\overline{{ }^{*} \text { Corresponding author: imiller@wcu.edu }}$
} 
Across Europe, recent environmental legislation has largely been derived from European Union (EU) Directives. These directives do not specify the manner in which the laws are to be written, but direct Member States of the EU to develop regulations to achieve a particularly set of outcomes [12]. Of particular importance to our current discussion is the Environmental Liability Directive of 2004 that was intended to prevent and remedy environmental damage to both land and water resources that pose a threat to the ecosystem and human health [12]. The Directive enhances the 'polluter-paysprinciple' in that it specifies that polluters should be responsible for implementing measures that prevent damage to natural resources and for remediating the damage that they have caused to the environment.

In order to carry out legislation based on the polluterpays-principle, the source of the contaminant(s) must be identified and linked to the responsible party(ies). In some cases, such as where a single source of a non-naturally occurring chemical is dispersed by a limited number of processes, it may be a relatively easy task to identify the polluter. More commonly, however, water resources are contaminated by multiple entities that discharged varying quantities of contaminants to the environment. Some of these entities may no longer exist but were a historic waste generator. Further complicating the issue is that toxic trace metals occur naturally in the environment, raising the question as to what the contaminant level was prior to pollution, and for which the PRPs should not be held liable [13]. A fallout of these complex, legal cases is that a waste generator may not only question whether they are a responsible polluter, but whether they should be held responsible for all of the damage to a particular resource [13].

While scientists have been conducting investigations into contaminant liability issues for decades, the increasing need to apply their investigative techniques to legal issues led in the 1990s to the field of environmental forensics. Wenning and Simmons [14] defined environmental forensics as the "systematic examination of environmental information to determine sources of chemical contamination, the timing of releases to the environment, the spatial distribution of contamination, and the potential responsible party(ies)".

The field of environmental forensics has grown over the past 20-years into a scientific subdiscipline in and of itself. During this time, it has become clear that the determination of contaminant sources to riverine ecosystems is a difficult, and potentially expensive, task. Even where the contaminant source appears obvious, detailed investigations have shown that additional, unexpected sources of trace metals may exist. For example, numerous studies during the 1970 s through the 1990 s found increased inputs of mercury $(\mathrm{Hg})$ to aquatic ecosystems in the Amazonian rainforest [15-18]. The assumption was that the increase in $\mathrm{Hg}$ inputs was related to widespread $\mathrm{Hg}$ amalgamation mining of placer gold deposits. Amalgamation mining involved the use of $\mathrm{Hg}$ to capture fine gold particles by forming dense amalgam grains that could be separated from the hydraulically lighter sediments. These amalgam grains were then heated (roasted), driving $\mathrm{Hg}$ off as a vapor and leaving a "purer form of the gold. In the process, $\mathrm{Hg}$ was lost to the riverine ecosystem. Malm [18], in fact, estimated that approximately 240 tons of $\mathrm{Hg}$ were released into the environment annually during the 1990s from mining operations in the Amazon of Brazil Amazon, Venezuela, Colombia, and Bolivia. Mercury was also found to be elevated in biota, including human hair, blood, and urine $[15,16,19]$. While gold amalgamation mining clearly contributed $\mathrm{Hg}$ to rivers in the Amazon (and many other places around the world), more detailed studies found that mining was not the sole source, or even the predominant source, of increased $\mathrm{Hg}$ inputs [20-23]. In fact, within some river basins, such as the Tapajós, $\mathrm{Hg}$ inputs were found to come primarily from the erosion of surface soils that had been enriched naturally by means of atmospheric deposition over geological time scales. The observed increases in $\mathrm{Hg}$ inputs to the studied rivers were induced, in part, by deforestation; only about $3 \%$ was derived from mining operations [22]. The point here is that while the termination of all $\mathrm{Hg}$ amalgamation mining may have slightly improved sediment and water quality, improvements would have been minimal because much of the $\mathrm{Hg}$ was derived from a separate, unexpected source.

The remediation of Contaminant Rivers is a major undertaking. In fact, rivers represent some of the largest Superfund sites in the U.S., and the costs of remediation are often in the hundreds of millions of dollars (US). As a result, significant effort has gone into developing methods to determine the source of contaminants, including trace metals, in rivers, most recently in the context of environmental forensics. The majority of the developed techniques rely on fingerprinting techniques that attempt to define trace metal sources by identifying one or more unique physical, mineralogical and/or chemical parameters that can uniquely distinguish a suspected source in the basin from all other sources. Fingerprinting techniques, however, are not the only methods that can be used to assess trace metal sources or their relative contributions to a river. A common question that arises, then, during the development of a remediation program is which methods are most effective at identifying trace metal sources in terms of both time and costs. Underlying this question is the understanding that whatever methods are used must withstand the scrutiny of legal debate which is often associated with remedial activities.

In this paper, a multidisciplinary four-component approach to the effective identification of the predominant sources of trace metals to river sediments is put forth. The approach is intended to integrate geomorphic, alluvial stratigraphic, and geochemical data that not only allows for the assessment of trace metal sources but insights into their transport and ultimate depositional locations of trace metals along the river valley.

\section{Methodological Approach}

Herein, it is argued that four types of analyses provide a time and cost-effective framework for the identification of trace metal sources and their relative contributions to aquatic environments. They include (1) the analysis of the river's recent alluvial stratigraphic architecture and 
geomorphic history, (2) the temporal correlation of geochemically characterized alluvial deposits to potential anthropogenic trace metal sources, (3) the analysis of the spatial variations in selected geochemical parameters, and (4) the use of geochemical and/or isotopic tracers to quantitatively estimate the contributions of trace metals from the defined natural and anthropogenic sources (Fig. 1). The four included components are not intended to be exhaustive. In fact, the approach utilized at any given site should be based on the multiple lines of evidence concept, in which additional methods and data (not described herein) are added to the investigation until there is "sufficient" confidence that all trace metal sources and their contributions have been effectively defined.

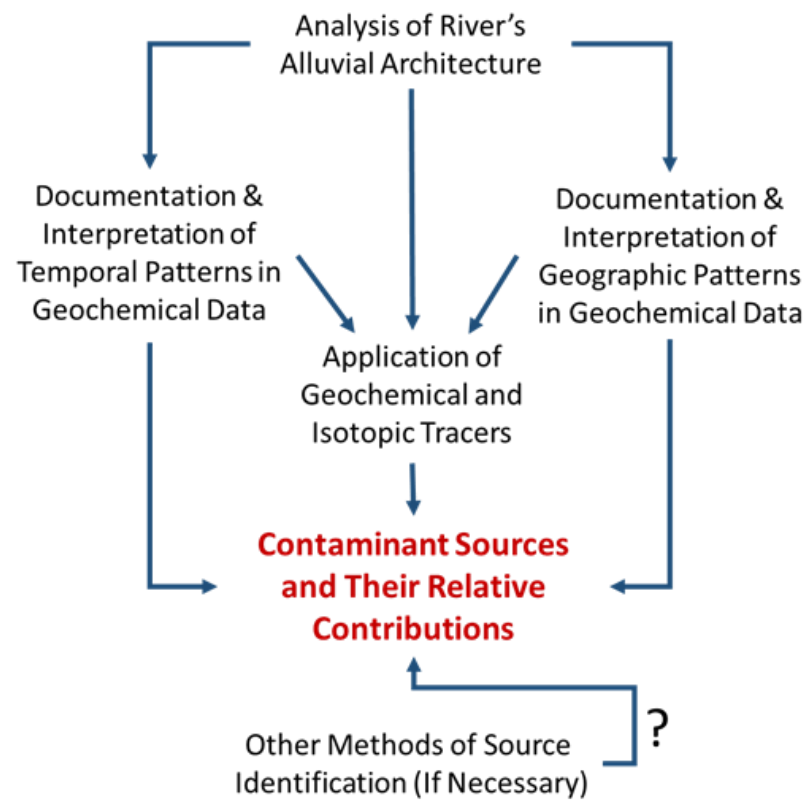

Fig. 1. Schematic diagram of the framework proposed for the assessment of trace metal sources and source contributions.

\subsection{Analysis of a River's Alluvial Architecture and Geomorphic History}

Rivers can be viewed, somewhat simplistically, as a network of channels that carry water and sediment from upland areas of a catchment to the basin mouth. Rather than being simple conduits, however, rivers continually erode and deposit sediments, both within the channel and, during floods, on the adjacent floodplain. These geomorphic processes create alluvial stratigraphic units (deposits) that not only consist of the sediments that enter the channel but sediment-associated trace metals. These alluvial (river) deposits, therefore, contain a record of trace metal inputs to the river [9,24,25].

Historically, the sampling of contaminated rivers largely ignored the fact that these alluvial deposits vary in terms of their sedimentological characteristics or age. However, more recent studies have shown that attempts to distinguish the relative proportions of trace metals derived from natural and anthropogenic sources are complicated by physical and biogeochemical processes that act on source materials as they are transported downstream through the river system. A particularly important process is hydraulic sorting that partitions the sediments, and the trace metal(s) they are carrying, into specific depositional environments within and along the river based on grain size and density [9]. Fine-grained sediments tend to be deposited in areas of low velocity, whereas coarser sediments in zones of higher velocity. The net effect of these processes is for trace metals to become partitioned during transport such that they are deposited into stratigraphic units characterized by distinct sedimentological traits that are characterized by concentrations that are significantly higher or lower than in the original source materials. In addition to hydraulic sorting, the original composition of the source materials may be affected by the addition of non-reactive constituents (e.g., organic matter, carbonates) into the deposited sediment, or by geochemical transformation processes including reductive/oxidative reactions (that may, for example, allow grains to be coated with $\mathrm{Fe}$ and Mn oxides and hydroxides). These processes are elementspecific, and depend on the local climatic, hydrologic, and geomorphic setting $[9,26]$

The preferential deposition of source materials also occurs over larger spatial scales. For example, relatively narrow, steep valley reaches have been shown to produce zones of limited sediment deposition (referred to as transport zones), whereas wide, low-gradient reaches produce zones of deposition and contaminant storage (depositional zones). Thus, in some environments, trace metal concentrations and storage may vary downstream as a function of the river's overall geomorphology, and the geomorphic processes that occur along Specific River reach.

The primary goal of analyzing the river's alluvial stratigraphic architecture and history is to identify, characterize and map the distribution of distinct, sedimentary deposits along the river valley. These deposits can subsequently be dated, as described below. Provided that sediment-trace metal relationships are known, the collected information provides insights into where sediment-associated metals from a specific source are likely to be deposited. For example, mine and mill tailings from $\mathrm{Cu}, \mathrm{Pb}$, and $\mathrm{Zn}$ ores commonly contain significant quantities of sulfide minerals (e.g., galena, sphalerite, and pyrite). These relatively dense mineral grains are typically deposited with coarse-grained alluvial sediments. In fact, these sulfide minerals may form contaminant placer deposits along the river [9]. The same holds true for $\mathrm{Au}$ or $\mathrm{Ag}$ amalgam grains associated with amalgamation mining. In contrast, trace metals associated with chemically reactive, fine-grained sediments will likely be deposited in areas of relatively low flow, such as on floodplains or in oxbow lakes (Fig. 2). Therefore, by characterizing the sedimentology and distribution of the deposits, it is possible to hypothesize as to where trace metals from a potential source are likely to be concentrated. 


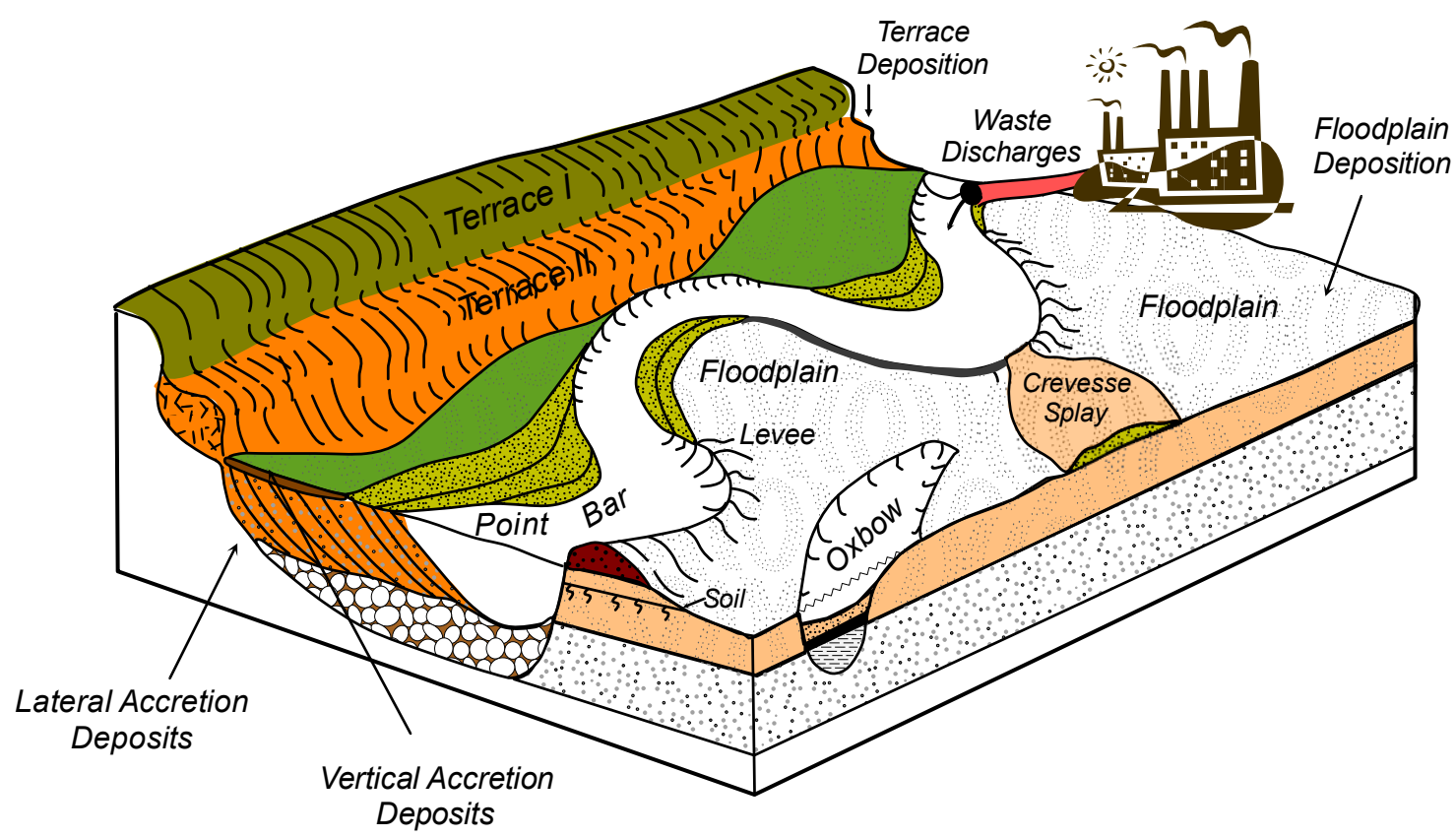

Fig. 2. Common types of alluvial deposits located along meandering streams. Each deposit (stratigraphic unit) possesses a unique sedimentology and, thus, trace metal content (figure modified from Miller et al. [37]).

In addition to the above, documentation of the river's alluvial architecture and history provides the foundation for the development of the temporal and spatial analyses described below. Thus, while such geomorphic and stratigraphic studies are often ignored in contaminant source analyses, they are critical components that should not be overlooked.

\subsection{Temporal Studies}

Once the alluvial stratigraphic deposits within the river valley have been defined and sedimentological and geochemically characterized, they can often be dated to determine their approximate age. Historically, absolute dating of the deposits primarily relied on radiocarbon methods characterized by a rather poor temporal resolution. However, deposit dating has significantly improved in recent years, and may include the use of other methods including ${ }^{137} \mathrm{Cs}$ and ${ }^{210} \mathrm{~Pb}$ analyses, dendrochronology techniques, the analysis of historic artifacts and sequential aerial imagery, and, perhaps of most significance, optically stimulated luminescence (OSL) techniques, to mention a few (see Stokes and Walling, [27] for a more detailed review). As a result, it is often possible to constrain the age of alluvial stratigraphic deposits to a few years. This makes it possible to compare the geochemical (trace metal) content of the deposits, both temporally and geographically, to the location and history of suspected anthropogenic trace metal sources. As an illustration, the hypothetical stratigraphy of a river valley containing two potential sources of lead $(\mathrm{Pb})$, is shown in Fig. 3. Stratigraphic units A1-A3 possess similar and relatively low $\mathrm{Pb}$ concentrations. The highest concentrations of $\mathrm{Pb}$ are found in unit $\mathrm{A} 5$, which was deposited between approximately 1900-1960, during which time an upstream industrial site (\#1) was operating.
This temporal correlation between high $\mathrm{Pb}$ concentrations in unit 5 and the industrial site \#1 suggests that it contributed at least some of the increased $\mathrm{Pb}$ observed in unit A5. Given that industrial site \#2 had yet to be built and was located downstream of cross-section B-B', it could not have contributed $\mathrm{Pb}$ to the site. Note, however, that the increase in $\mathrm{Pb}$ concentrations began to occur in unit A4, which predates the operation of industrial site \#1, suggesting that another, unidentified source of $\mathrm{Pb}$ may have existed upstream of the cross-section B-B'. The illustration shows that it is important to develop chronologies of trace metal inputs for multiple locations. Selection of these sites should minimize the number of locations needed to effectively define inputs to the river from all potential trace metal sources. The historical record should also extend into the past for hundreds of years, if possible, to ensure that natural variations in trace metal inputs are adequately characterized.

The methods, assumptions, and uncertainties inherent in developing a record of the temporal variations in trace metal inputs to a river can be found in Macklin and Klimek [28], Hudson-Edwards et al. [29], Tobin et al. [30], Miller and Orbock Miller [9], Pease et al. [31], Du Laing et al. [32], Matys Grygr et al. [33,34], and Ferrand et al. [35]. In general, it involves three primary tasks, including the stratigraphic and sedimentological characterization of the river deposits, the sampling and geochemical analysis of the deposits for trace metals and other parameters, and the application of absolute dating methods to determine the approximate age of the deposits in "calendar" years.

Contaminant chronologies can be developed using any undisturbed sequence of river sediments, as well as sediments obtained from wetlands, lakes, and reservoirs that are physically linked to the river. Perhaps the most detailed chronological records have been developed using reservoir deposits and overbank floodplain deposits. The 
latter deposits (also referred to as vertical accretion deposits) are characterized by successive thin layers of sediment produced by the deposition of suspended sediments from floodwaters that inundate the floodplain surface (Fig. 2). The process results in a sequence of layers in which younger sediments overlie older sediments producing a trend in which the age of the sediment systematically increases with depth. Unfortunately, the relationship between depth and unit age is not perfect because deposition only occurs during floods. Nonetheless, detailed records of trace metal loadings, as shown in Fig. 3, have been produced $[28,35,34]$.

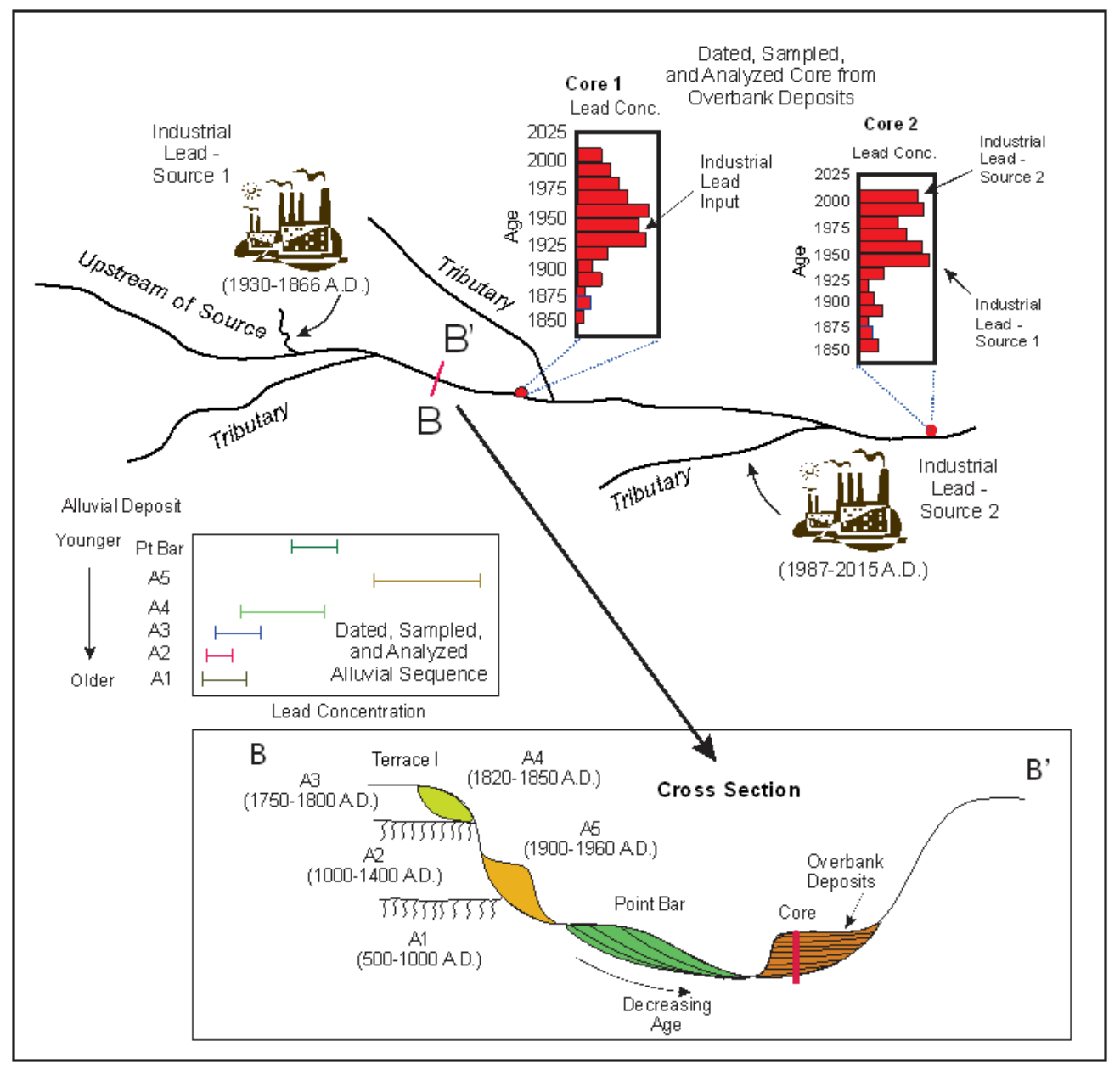

Fig. 3. Illustration of the spatial and temporal correlation of between alluvial stratigraphic units and industrial sources (figure modified from National Academy of Sciences [36].

\subsection{Spatial Studies}

One of the oldest and most extensively utilized methods of determining a point source of trace metal contamination is to examine its spatial distribution along the river. In most instances, the spatial distribution of the trace metal is examined in terms of its concentration in the channel bed or floodplain sediments. The presumption is that the highest concentrations of the metal will be located closest to the source, and decrease with distance from the site. In general, the spatial approach to source determination along rivers involves the collection and analysis of samples from multiple sites distributed along the channel and its associated features, and the subsequent plotting of the derived concentration data to document geographical patterns in elemental content. Point sources can then be identified by a distinctive trend in which low concentrations occur upstream of a source and abruptly increase in concentration where the trace metal(s) enter the channel. Concentrations subsequently decrease semi- systematically downstream from the source as a result of (1) the hydraulic sorting of contaminated particles, (2) dilution resulting from the mixing of contaminated particles with "clean" sediment from tributaries and eroded banks, and the dispersal of sediment-borne contaminants over a larger area, and/or (3) the deposition and subsequent storage of the contaminants within the channel bed or floodplain, a process that removes the contaminants from further transport. In addition, geographical patterns in alluvial sediments are often influenced by geochemical processes, such as precipitation, sorption on to reactive particles, and/or the oxidation/reduction of mineral grains. The accumulation of a contaminant in biota also has been cited as a control, but its influence is typically negligible along most rivers. In many cases, input from the identified source is supported by a comparison of the concentration of the contaminant within the suspected source materials. As an illustration, Fig. 4 shows the distribution of $\mathrm{Pb}$ and 
Barium (Ba) along the Big River in southeastern Missouri. The abrupt upstream increase in $\mathrm{Pb}$ was interpreted to result from the influx of mining and milling wastes within the St. Francois mining district. Secondary increases in $\mathrm{Pb}$ spatially correspond to increases in $\mathrm{Ba}$, which have been interpreted to represent the influence of $\mathrm{Pb}$ from earlier mining operations within the Barite mining district [38].

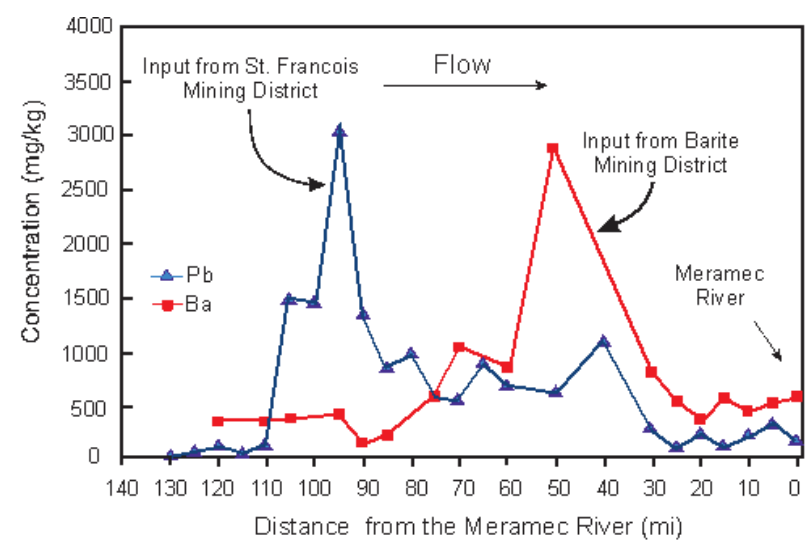

Fig. 4. Downstream trends in lead and barium concentration along the Big River, Missouri, USA. Abrupt increases in concentration reflect input of metals from mining operations (figure modified from Integral [38].

Although the spatial analysis of trace metal concentrations is easy to use and often provides important insights into the sources of trace metals to a river, the approach is plagued by the fact that the influx of trace metals from multiple sources can create overlapping spatial patterns that make it difficult to identify where the metals are derived. Such overlapping patterns are particularly common in mineralized river basins where metals may be derived from both mining wastes and mineralized rocks that underlie the basin. In fact, exploration geochemists often analyze spatial trends in trace metal concentrations in rivers to identify the location and grade of ore deposits. To help alleviate this problem, downstream variations in the ratios of trace metal concentrations may be used. For example, within the Rio Loa basin of northern $\mathrm{Chile}, \mathrm{Cu} / \mathrm{Sb}$ ratios were effective at differentiating between mining and geogenic trace metal sources. High $\mathrm{Cu}$ concentrations were associated with waste materials from local $\mathrm{Cu}$ mines, whereas elevated $\mathrm{Sb}$ concentrations were associated with natural mineralized rocks, particularly sediments derived from the El Tatio Geyser Basin [39]. In other instances, it may be possible to utilize the unique element or mineral associated with a specific source. The use of Ba along the Big River in Missouri is an example, as barite was not particularly prevalent in the mine wastes from the St. Francois mining district. Alternately, spatial trends in local enrichment factors (LEFs, see below) can be used to filter out the input of trace metals from natural sources, along with changes in the grain size and lithology of the source materials during transport through the river.

Another potential problem encountered while interpreting spatial data is that the deposition of sediment and sediment-associated trace metals may not decrease systematically downstream, but may reflect changes in flow conditions along with the drainage network (as observed for transport and sedimentation zones). Moreover, in mining areas, the influx of trace metals from mineralized rocks may produce downstream trends characterized by highly variable trace metal concentrations or ratios, as well as the preferential deposition of trace metals in deposits of specific grain size or density.

To compensate for the influence of grain size, density, or natural geogenic variability, spatial variations in concentration within the overbank deposits is often examined for a specific grain size fraction (such as the silt and clay-sized, $<63 \mathrm{~m}$ fraction), or a bulk concentration normalized by the percent of fine sediment in the sample [40]. An alternative approach used to differentiate between natural and anthropogenic sources of trace metals is to examine spatial variations in enrichment factors (EFs).

One of the most common methods of calculating EF values is the "double-normalization" technique, mathematically expressed as:

$$
\mathrm{EF}=\left(\mathrm{M} / \mathrm{M}_{r e f}\right) /\left(\mathrm{M} / \mathrm{M}_{r e f}\right)_{b c}
$$

where $\mathrm{M}$ is the target trace metal of interest, Mref is a conservative reference element, and $b c$ refers to the average concentrations of the target metal and reference element in uncontaminated background materials. Commonly utilized reference elements include $\mathrm{Al}, \mathrm{Fe}, \mathrm{Li}$, $\mathrm{Rb}, \mathrm{Si}, \mathrm{Ti}$, and, more recently, Co. Theoretically, the method addresses variations in both grain size and particle mineralogy. Aluminum, for example, is a significant element in aluminosilicate minerals, including finegrained $(<\sim 2 \mathrm{~m})$ clay minerals, and therefore reflects both grain size and elemental composition of the sediment $[26,41,42]$.

Historically, elemental average concentrations were based on those measured in continental crustal rocks (bc, Equation $1[26,43,44]$. More recent studies have shown, however, that the use of these elemental averages tends to result in large errors [44] because (1) the elemental concentrations determined from continental crustal rocks do not adequately represent that rocks that underlie the basin of study, and (2) the metal concentrations measured in the source metals rocks) will be altered by physical and/or biogeochemical processes, thereby changing the nature of the source sediments as they are transported downstream (as described earlier). Given these shortcomings, more recent studies have argued for the use of local enrichment factor (LEF) $[26,43,44]$, in which:

$$
\mathrm{LEF}=\mathrm{M}_{\mathrm{S}} / \mathrm{M}_{\mathrm{BG}}
$$

where $\mathrm{M}_{\mathrm{S}}$ is the concentration of the target metal of concern in the sample, and $\mathrm{M}_{\mathrm{BG}}$ is the concentration of the metal of concern in local, non-anthropogenically polluted, background sediments. $\mathrm{M}_{\mathrm{BG}}$ is empirically predicted using a background function, such that:

$$
\mathrm{M}_{\mathrm{BG}}=\mathrm{f}\left(\mathrm{M}_{r e f}\right) \text {. }
$$


In most instances, background functions are defined by bivariate regression equations between the concentrations of the target metal in the unpolluted sediments and a parameter that accounts for changes in metal concentrations during sediment transport and deposition. The most common functions involve grain size, organic matter content, or the concentration of a conservative reference element. An advantage of calculating and using local enrichment factors in the development of trace metal chronologies is that they not only provide insights in when contamination occurred but the relative magnitude of the contamination that occurred in comparison to local background values.

It is important to recognize that the resolution of the spatial variations in downstream trends in trace metal concentrations, elemental ratios, and LEFs values depends on both the number and location of the samples that have been collected along the river. Differences in sampling frequencies and locations may yield differing results. It is therefore advantageous to collect as many samples as possible, particularly up and downstream of major tributaries.

\subsection{Use of Geochemical Tracers to Determine Source Contributions}

The approaches described above identify contaminant source(s) by spatially or temporally linking elevated concentrations (or differences in elemental ratios or LEFs) to suspected contaminant sources. Where multiple sources exist, the assumption is that the magnitude of the increases or decreases in metal values will provide qualitative insights into the relative contributions of contaminants from each of the delineated sources. While the approach is logically intuitive and easily understood, more quantitative estimates are often required, particularly when the analysis is being conducted as part of an environmental forensic investigation. During the past decade, there has been a dramatic increase in the use of environmental tracers to assess the provenance (source), movement, and fate of sediment and sediment-associated contaminants within rivers. With regards to alluvial sediments, a tracer is defined as a unique sediment-associated parameter or set of parameters that can distinguish a particular sediment type from other sediments in the basin. The tracer can, therefore, be used to track the movement and cycling of specific sediments from their point of origin through the river over varying temporal and spatial scales [37]. The term 'tracer' is often used synonymously with fingerprint. However, the term fingerprint is used in the geomorphological literature refer to a specific type of analysis (referred to as fingerprinting studies), which are described below. With regards to environmental forensic studies of contaminated rivers, the application of tracers or fingerprints has evolved significantly over the past decade and has now become the predominant method for quantitatively determining source contributions. With regards to alluvial (river) sediments, two types of analyses have evolved over the past two decades and, unfortunately, there has been little integration in the development of the two approaches. One approach involves the use of the concentration of multiple elements to create unique source area fingerprints and then applies statistically-based mixing models to the data. The second approach relies on the use of stable isotopic data, which is typically combined with analytical mixing models. Both types of investigation have benefitted greatly from recent scientific advances in analytical chemistry, which allows for the rapid analysis of large numbers of samples for a wide range of elements and measurements of isotopes that could not be analyzed in the past. Another important advantage of using geochemical tracers/fingerprints is that the analysis can be completed relatively quickly in comparison to many techniques, and can be applied to historic sedimentary deposits retrospectively to determine changes in sediment and contaminant provenance at a site through time.

\subsubsection{Multi-elemental Fingerprinting Analyses}

As the name implies, multi-elemental fingerprinting studies utilize variations in the concentration of multiple elements to develop a unique fingerprint for a specific sediment source and then allow sediment from that source to be distinguished from other sediment sources in the basin. It is worth noting that the method tracks the sediments associated with a trace metal source and not the trace metal of concern. Fingerprinting studies are most often applied to diffuse sources of sediment in the basin, although their application to other types of problems is increasing. Conceptually, fingerprinting studies are based on the fact that upland areas of a catchment can be spatially subdivided into specific sediment sources on the basis of its underlying geology or soil types. Each of these sediment sources can be eroded, after which the generated sediments are transported, often intermittently, to the river channel. As the sediments are transported downstream through the channel to a depositional point, the particles from all of the source areas are combined such that the sediments within the depositional unit represent a mixture of particles from all of the source areas in the basin. The physical and geochemical composition of this sediment mixture (which we will refer to as river sediment) depends on the composition of the source area sediments and the relative amount of sediment that is contributed to the deposit from each source area; if both are known, it is possible to predict what the composition of the mixture will be. In our case, however, the objective is to determine the relative amount of sediment, and sediment-associated trace metals, that a particular sediment source contributed to the deposit. This type of calculation represents a linear inverse problem [45]. The problem is typically solved using some form of inverse or unmixing model that requires that the composition of both the source and river sediments be known for a selected set of parameters, and then defines the mixing proportions from each source by adjusting the contributions such that the values of the parameters most closely match the values observed in the studied river sediment [45].

In general, the fingerprinting method involves five key steps (after Zhang et al. [46]): (1) delineation and 
characterization of sediment sources within the basin, (2) the selection of the fingerprinting parameters (elements) that most effectively discriminate between sediments of the defined sources, (3) the collection of river sediment on the basis of the timeframe under consideration, and its subsequent characterization for the selected fingerprinting properties, (4) the determination of sediment provenance (source) using numerical modeling procedures, and (5) assessment of the uncertainty inherent in the modeling results. Although a wide range of physical, mineralogical, and geochemical parameters have been used as fingerprinting parameters to determine the source of the sediments and their associated metals [37, 47], most environmental forensic analyses utilize the concentration of multiple, conservative elements to develop an effective fingerprint.

Geochemical fingerprinting studies have been applied to a wide range of river sediments, and the river sediments that are selected determine the timeframe of the source analysis. The timeframe may range from recent, instantaneous suspended sediment samples collected during a specific part of a flood event to river sediments deposited within floodplains or riparian wetlands during an entire flood and that may be hundreds or even thousands of years old. In addition, overbank floodplain deposits or reservoir sediments can be incrementally collected and analyzed to determine changes in sediment source through time (Fig. 5).

The overwhelming majority of fingerprint studies have been conducted to determine the source of sediments and sediment-associated contaminants from diffuse sources located throughout a river basin. The approach, then, is perhaps most applicable to the assessment of trace metals from natural mineralized rocks as well as urban pollutants and agricultural chemicals (e.g, fertilizers, pesticides, sewage amendments). It is possible, however, to include point sources of trace metals in the analysis to determine their contribution to a river. Moreover, the approach has been used to assess the relative inputs from a point source by characterizing changes in elemental concentrations from up- to downstream of a contaminant input point. In most instances, the point in contaminant influx is taken to be the mouth of a tributary [48, 49].

A common criticism in the application of multielemental fingerprinting studies is that the statistical mixing models used to estimate the relative contributions of sediment from each of the defined sources resulted in values that were not unique. Rather, the results represented statistical estimates, for which there was an infinite number of possibilities. This problem has been referred to as the equifinality problem. Moreover, the results were often considered to possess considerable, but unquantifiable error, particularly where one source contributed little $(\sim 0 \%)$ or all $(100 \%)$ of the sediment. During the past decade, considerable progress has been made in addressing this problem, and most statistical fingerprinting approaches are now able to quantify the uncertainty in the modeling results. In addition, the influence of grain size, organic matter content, and other factors on elemental concentrations has also been reduced. As a result, it can be argued that multi-element fingerprinting methods are highly effective.

\subsubsection{Source Analysis using Isotopic Tracers}

A wide range of stable isotopes have been applied to hydrological and geological investigations. The isotopes that have, perhaps, been most widely used are $\mathrm{H}, \mathrm{C}, \mathrm{N}, \mathrm{O}$, $\mathrm{S}$, and $\mathrm{Si}$. However, with regards to sediments, and the analysis of sediment and trace metal sources, radiogenic isotopes (e.g., $\mathrm{Sr}, \mathrm{Nd}$, and $\mathrm{Pb}$ ) have historically been of most importance. Radiogenic isotopes are the daughter products of the decay of a radioactive parent. Their use as effective tracers stems from several key characteristics: (1) they can be accurately and precisely determined, (2) they exhibit isotopic abundances that vary widely within geological materials, allowing for the fingerprinting of both natural and anthropogenic materials, and (3) they are not significantly fractionated by physical, chemical or biological processes. This latter trait is important because the isotopic ratios (fingerprints) of the source sediments will remain largely intact during the erosion, transport, deposition, and diagensis of the sediment, allowing the isotopic composition of river sediments to reflect the mixing of materials from all of its sources within a river basin. With regards to environmental forensic investigations, the radiogenic isotopes of $\mathrm{Pb}$ have been the most extensively utilized. In fact, lead isotopes have been extensively used to determine the sources of $\mathrm{Pb}$ in a wide range of media, including air and aerosols, snow and ice, soils, lacustrine and reservoir deposits, wetlands and peat, plants, mosses, and tree rings, human tissues and blood and other biota (see Miller et al. [37] for extensive list of references). Moreover, because $\mathrm{Pb}$ is commonly associated in both Earth materials and man-made products with other toxic trace metals, $\mathrm{Pb}$ isotopes can often be used to assess the source of these other metals. A key advantage of using radiogenic isotopes, including those of $\mathrm{Pb}$, is that they can provide quantitative estimates of the contribution of $\mathrm{Pb}$ in sediment as well as the other media of interest. It is for this reason that where possible, radiogenic isotopes, particularly those of $\mathrm{Pb}$, should be applied in the forensic investigation of contaminated river sediments.

Given its widespread application, and its effectiveness at tracking sediment-associated $\mathrm{Pb}, \mathrm{Pb}$ isotopes are discussed below as an example of how isotopic tracers can be applied to determine the source(s) and source contributions of $\mathrm{Pb}$ in river basins. More detailed reviews of the use of radiogenic isotopes in the environmental forensic investigation of contaminated rivers can be found in Miller et al. [37], whereas Bird [50] reviews the application of $\mathrm{Pb}$ isotopes to riverine environments.

Lead has three radiogenic isotopes, ${ }^{206} \mathrm{~Pb},{ }^{207} \mathrm{~Pb}$, and ${ }^{208} \mathrm{~Pb}$, derived from the radioactive decay of ${ }^{238} \mathrm{U},{ }^{235} \mathrm{U}$, and ${ }^{232} \mathrm{Th}$, respectively; ${ }^{204} \mathrm{~Pb}$, has no known radiogenic parent. The isotopic abundances of $\mathrm{Pb}$ in geological materials are reported in terms of ratios (e.g., ${ }^{206} \mathrm{~Pb} /{ }^{204} \mathrm{~Pb}$ ). For most environmental studies, only the radiogenic isotopes of $\mathrm{Pb}$ are used as geochemical tracers, in part, because the abundance of ${ }^{204} \mathrm{~Pb}$ is relatively low, making it difficult to accurately measure. The analyses of sediment-associated $\mathrm{Pb}$ sources presume that the analyzed river sediment contains a mixture of $\mathrm{Pb}$ from all of the 
potential $\mathrm{Pb}$ sources in the basin and that the relative abundance of the radiogenic $\mathrm{Pb}$ isotopes in the sediment depends on the relative contributions of $\mathrm{Pb}$ from each source. This assumption is nearly always met as the fractionation of $\mathrm{Pb}$ isotopes by physical, chemical and biological processes is negligible.

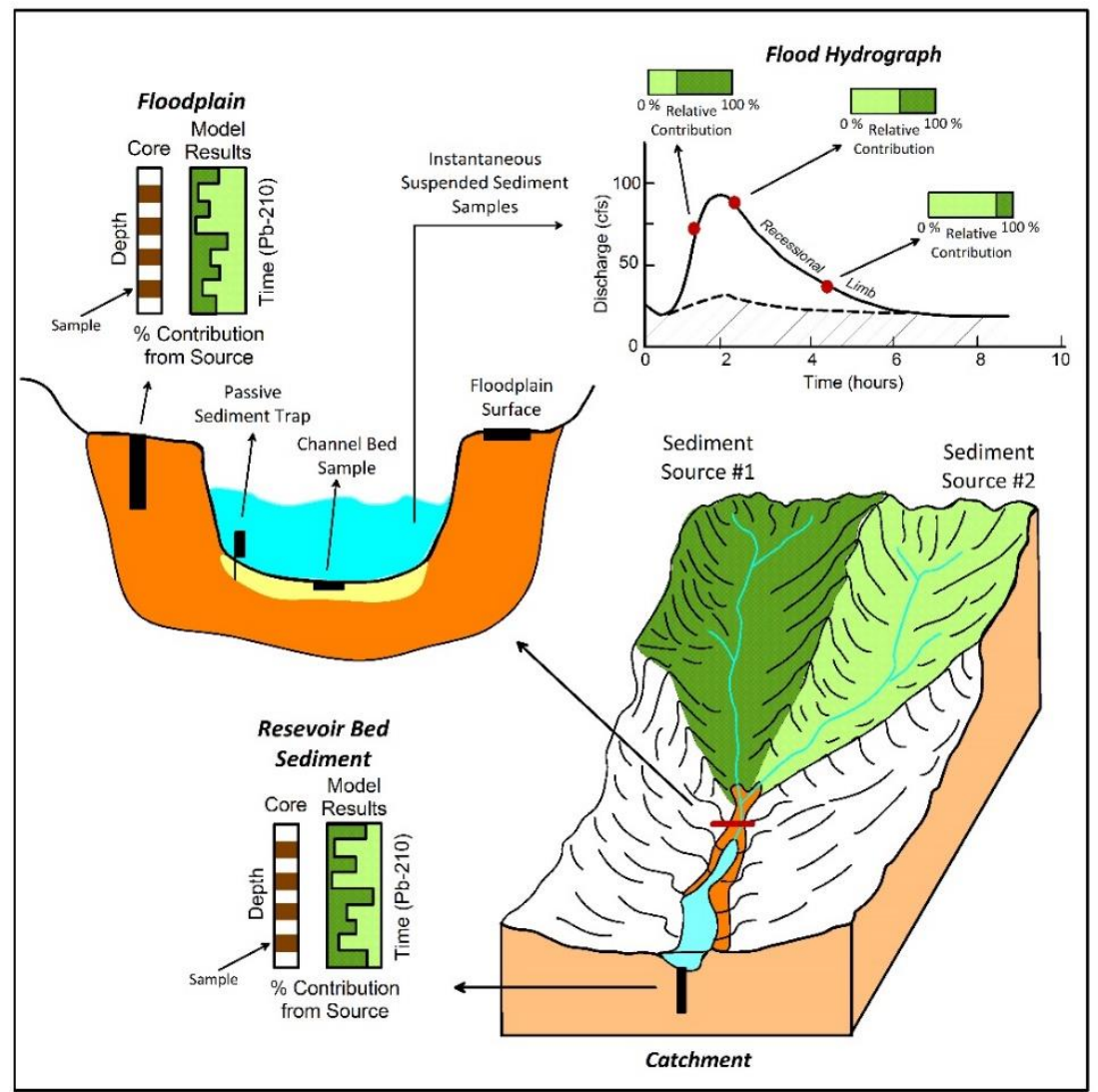

Fig. 5. Summary of commonly used sediments for the analysis of trace metal sources using multi-elemental fingerprinting methods (figure from Miller et al. [37]).

The quantification of $\mathrm{Pb}$ contributions from a particular source is often initiated by plotting the isotopic data collected from suspected $\mathrm{Pb}$ sources and the river sediments of interest on three-component (bivariate) scatter diagrams depicting differences between two isotopic ratios (Fig. 6) [51,52,50]. Ideally, Pb sources will exhibit a narrow range of isotopic ratios, which differ from the other suspected sources and from the sediments collected from within the river. In this case, the $\mathrm{Pb}$ isotopic ratios serve as effective fingerprints (tracers) of the suspected $\mathrm{Pb}$ sources. Moreover, if the isotopic ratios of the river sediments plot along a linear trend between two of these isotopic end-members, then the trend is interpreted as a mixing curve, and the $\mathrm{Pb}$ within the river sediments is assumed to be primarily derived from the sources that form the two end-members of the line. In many cases, one end-member of the mixing curve represents $\mathrm{Pb}$ from the bedrock that underlies the river basin, whereas the other represents $\mathrm{Pb}$ from a significant anthropogenic source [50]. The average signature of the "geogenic" $\mathrm{Pb}$ sources can be determined by analyzing uncontaminated alluvial sediments in the basin, such as sediments found in uncontaminated alluvial terraces (comprised of pre-historic sediments) [52], floodplain sediment found at depth within a sediment core that predates anthropogenic contamination [48], or the direct analysis of the underlying bedrock [52].
As mentioned earlier, a significant advantage of using $\mathrm{Pb}$ isotopes as tracers is that accurate estimates of the relative contributions of $\mathrm{Pb}$ can be determined analytically. When there are only two sources of $\mathrm{Pb}$, and the mixing curve is linear, the contributions from the two end member sources can be calculated using a simple binary model $[48,53]$ that takes the form of:

$$
\% A=\frac{\left({ }^{20 x} P b / 20 x_{P b}\right)_{S}-\left({ }^{20 x} P b /{ }^{20 x} P b\right)_{A}}{\left({ }^{20 x} P b /{ }^{20 x} P b\right)_{B}-\left({ }^{20 x} P b /{ }^{20 x} P b\right)_{B}}
$$

where $\% A$ is the contribution of source $\mathrm{A}$ in a sample and ${ }^{20 x} \mathrm{~Pb} /{ }^{20 x} \mathrm{~Pb}$ and ${ }^{20 x} \mathrm{~Pb} /{ }^{20 x} \mathrm{~Pb}$ are the average ratios in the sample (S) and the two end-member sources, A and B.

Within larger river systems contaminated by multiple anthropogenic $\mathrm{Pb}$ sources, well-defined mixing lines do not exist on binary scatter plots. In these cases, it is likely that multiple geogenic or anthropogenic $\mathrm{Pb}$ sources exist. As a result, estimating the relative contribution of $\mathrm{Pb}$ in the alluvial sediments of the river from the identified sources becomes more difficult. This problem has been overcome by subdividing and analyzing the data on the basis of located geographical areas or time periods (ref). In addition, the use of isotopic tracers can be combined with the multi-elemental approach describe above. For example, Bird et al. [54] used a two-tiered approach to assess the origins of $\mathrm{Pb}$ within sediments of the River Maritsa catchment of Bulgaria and Turkey. Lead isotopic 
data were used to assess the contributions of $\mathrm{Pb}$ to the channel from mining operations within smaller tributary basins. However, at a larger spatial scale, where highly variable $\mathrm{Pb}$ isotopic values inhibited the use of a binary isotopic approach, the sources of the $\mathrm{Pb}$ were determined using multi-element geochemical fingerprinting methods (described in the section above).

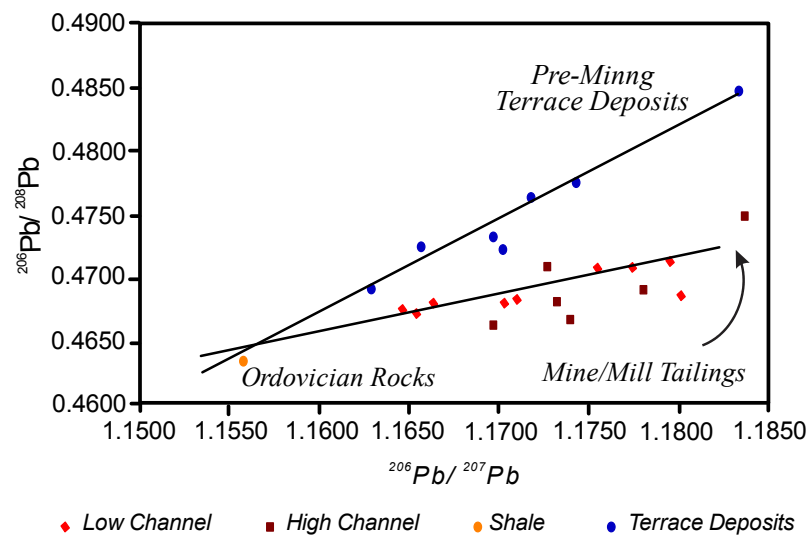

Fig. 6. Bivariate plot of lead isotopes. Background lead was characterized using samples from alluvial terrace deposits that predate mining. The onset of mining results in the influx of $\mathrm{Pb}$ from mine and mill tailings. The influx is reflected in a new source of $\mathrm{Pb}$ in the channel bed. Thus, samples plot along a new mixing line (figure modified from Miller et al. [52]).

Lead isotopic data are often combined with $\mathrm{Pb}$ concentration data (see, for example, Shepard et al. [55]). In doing so, it is possible to assess both changes the source of the $\mathrm{Pb}$ as well as the degree to which the $\mathrm{Pb}$ sources have contaminated the river. Moreover, because the predominant sources of $\mathrm{Pb}$ also served as the predominant sources of other toxic trace metals (e.g., As, Cd, Ni, Zn), $\mathrm{Pb}$ isotopes can be used to determine the sources of these metals as well. However, this is not always the case, and in some instances, the isotopic composition of $\mathrm{Pb}$ in contaminant sources cannot be distinguished from $\mathrm{Pb}$ naturally found in the underlying Earth materials. For example, within the Rio Loa basin of northern Chile, the $\mathrm{Pb}$ isotopic composition of $\mathrm{Cu}$ mine tailings and ore deposits was similar to that found in other rock types in the basin, including those associated with a local geyser basin, inhibiting the use of $\mathrm{Pb}$ isotopes as an effective tracer.

Before the 1990s, the investigation of many of the other isotopic systems (e.g., those associated with the transition and post-transition elements) was hindered by an inability to precisely measure their abundance in Earth materials. However, recent advances in analytical chemistry, including the advent of the MC-ICP-MS, have led to the precise measurement of a wide range of nontraditional stable isotopes, or non-CHONS (referred to because they are not one of the five most studied isotopic systems) [56]. The ability to accurately measure the isotopic abundances of these non-traditional isotopes in geological materials has opened up a whole new field of research into their use as tracers of contamination and to gain insights into biogeochemical processes. The intent with regards to environmental forensics is to develop direct methods to determine the source and cycling of toxic metals in sediments, soils, and water.

The application of these non-traditional isotopes as tracers of contaminant source in river sediments is much more complicated than that of $\mathrm{Pb}$, and most other radiogenic isotopes. In the case of $\mathrm{Pb}$, isotopic fractionation by industrial or biological processes is negligible; the $\mathrm{Pb}$ isotopic composition of man-made materials (e.g., as a battery) reflects the ore deposits from which the $\mathrm{Pb}$ was derived. Given that the $\mathrm{Pb}$ isotopic signature of the ores deposits typically differs from most other types of rocks, the $\mathrm{Pb}$ in man-made products is often unique. Moreover, $\mathrm{Pb}$ isotopic ratios measured within a sample of river sediment is a function only of the mixing of $\mathrm{Pb}$ from different sources, allowing for the relatively easy assessment of $\mathrm{Pb}$ contributions from each source. In contrast, the use of the non-traditional isotopes as a tracer is complicated by multiple physical and biological fractionation processes, which not only vary between elements, but the environmental conditions that exist within the river, and the physical, chemical and biological processes to which the metals were subjected. Thus, detailed investigations into the cycling of the utilized isotopes are required for their effective application. Nevertheless, several isotopic systems appear to hold significant promise with regards to the assessment of contaminated river sediments, including $\mathrm{Cu}, \mathrm{Hg}$, and $\mathrm{Zn}$ [37].

As an example, interest in the use of $\mathrm{Zn}$ isotopes as a forensic tracer in rivers stems from that fact that: (1) $\mathrm{Zn}$ occurs in a wide range of materials including mining and refining products and wastes, steel processing plants, coal-fired power plants, vehicles, urban waste incinerators, car tires, and other constituents in urban runoff, and (2) $\mathrm{Zn}$ is often associated with $\mathrm{Cd}$ and $\mathrm{Pb}$ in natural and anthropogenic materials, and can therefore be used to determine the source of these trace metals. The potential to use $\mathrm{Zn}$ isotopes to determine to the source of $\mathrm{Zn}$ in sediments and soils rests, in part, on the fact that the $\mathrm{Zn}$ isotopic composition of some anthropogenically produced materials can be distinguished from that occurring naturally in rocks and minerals. In addition, the fractionation of $\mathrm{Zn}$ is dominated by mass-dependent processes, such as evaporation, condensation, and electroplating, which when associated with industrial activities, can be measured. Fractionation may also occur at low temperatures during its biogenic uptake by microorganisms and other biotas [57,58], diffusion processes [59], adsorption onto inorganic and organic surfaces[58,60], and mineralization [61,62] (Table 6.1). If these new isotopic abundances (following fractionation) can be linked to a specific industrial process, then it is possible to use $\mathrm{Zn}$ isotopes to determine where the $\mathrm{Zn}$ from that process is currently located along a river and how much of the total $\mathrm{Zn}$ was derived from it [63-65].

The use of these non-traditional isotopes as tracers of metals in riverine sediments is still in the developmental stages, and in spite of some notable successes, their use will likely be limited to a supportive role in environmental forensic investigations during the near future. Nonetheless, the fact that these non-traditional isotopic systems can provide a wealth of information on the 
source, dispersal, and biogeochemical cycling of toxic trace metals that cannot otherwise be obtained, suggesting that their use is likely to grow exponentially in the coming years.

\section{Conclusion}

Environmental forensic investigations have increasingly relied on the use of geochemical and isotopic fingerprinting methods to determine the source and source contributions of trace metals in contaminated rivers. Recent advances in analytical chemistry have enhanced by the application of geochemical fingerprinting by allowing for the rapid, multi-elemental analysis of sediment samples, and by continually improving upon the accuracy and precision of measuring the isotopic abundances in Earth materials. In addition, it is now possible to determine the abundance of non-traditional isotopes in sediments. Although fractionation makes the use of these isotopic systems more complicated to use for source determination, recent studies show that some isotopes (e.g., those of $\mathrm{Cu}, \mathrm{Hg}$, and $\mathrm{Zn}$ ) hold considerable promise with respect to river sediments. In light of the above, geochemical and isotopic fingerprinting techniques are likely to remain the method of choice to determine trace metal sources and source contributions riverine sediments. However, the use of fingerprinting techniques requires an understanding of the natural and anthropogenic sources that exist within the basin; sources cannot be fingerprinted if they have not been tentatively defined. Potential sources of trace metals within the basin can be qualitatively identified using the widely used and accepted, but underutilized spatial and temporal methods described herein. These temporal and spatial methods, when combined with an analysis of the river valley's alluvial architecture, not only provide insights into potential trace metal sources, but (1) the potential partitioning of source materials into specific depositional environments, (2) the distances and rates of trace metal transport, and (3) the location of geochemical hotspots along the river valley.

Where the above methods do not fully identify the sources or source contributions for trace metals to a river, it will be necessary to utilized other types of physical or mineralogical tracers or source attribution methods, such as the occurrence of unique minerals within a source materials, geochemical speciation data, particle size or microtextures, and/or geomagnetic information (see D’Daen et al. [47], for examples).

\section{References}

1. USEPA, The Incidence and Severity of Sediment Contamination in Surface Waters of the United States, US Environmental Protection Agency, Office of Science and Technology, Washington D.C. (2004)

2. O.I. Davutluoglu, G. Seckin, C.B. Ersu, T. Yilmaz, B. Sari, Journal of Environmental Management 92, $2250-2259$ (2011)
3. D. Relic, D. Dordevic, S. Sakan, I. Andelkovic, A. Pantelic, R. Stankovic, A. Popovic, Environmental Monitoring Assessment 85, 7627 (2013)

4. S. Sakan, D. Dordevic, Trace Elements: Environmental Sources, Geochemistry and Human Health, New York, 117-134 (2012)

5. S.M. Sakan, D.S. ĐorĐević, M.M. Lazić, M.M. Tadić, Journal of Environmental Science and Health, Part A 47, 109 (2012)

6. S. Sakan, D. Dordevic, Metal Contamination: Sources, Detection and Environmental Impact, edited by $\mathrm{S}$. Hong-Bo, Nova Science Publishers, Inc, New York, 119-155 (2013)

7. R. Gibbs, Geological Society of America Bulletin 88, 829 (1977)

8. M. Martin, M. Meybeck, Marine Chemistry - MAR CHEM 7, 173 (1979)

9. J.R. Miller, S.M.O. Miller, Contaminated Rivers: A Geomorphological-Geochemical Approach to Site Assessment and Remediation, Springer Science \& Business Media (2007)

10. S. Comoro, G. Vaccaro, E.D. Dapitani, B.W. Bawlik, Chemosphere 95, 329 (2014)

11. B.L. Murphy, R.D. Morrison, Introduction to Environmental Forensics 2nd ed., Elsevier Burlington MA (2007)

12. S.M. Mudge, Environmental Forensics, The Royal Society of Chemistry, 1-16 (2008)

13. A. Kanner, R.D. Morrison, Environmental Forensics: Proceedings of the 2011 INEF Conference, The Royal Society of Chemistry, 1-1 (2012)

14. R. Wenning, K. Simmons, Environmental Forensics 1, 1 (2000)

15. D. Cleary, L. Thornton, N. Brown, G. Kazantzis, T. Delves, S. Worthington, Nature 369, 614 (1994)

16. H. Akagi, O. Malm, F.J.P. Branches, Y. Kinjo, Y. Kashima, J.R.D. Guimaraes, R.B. Oliveira, K. Haraguchi, W.C. Pfeiffer, Y. Takizawa, H. Kato, Water, Air, and Soil Pollution 80, 85 (1995)

17. O. Malm, F.J.P. Branches, H. Akagi, M.B. Castro, W.C. Pfeiffer, W. Bastos, H. Kato, Science of The Total Environment 11, 141 (1995)

18. O. Malm, Environmental Research 77, 73 (1998)

19. J. Lebel, M. Roulet, D. Mergler, M. Lucotte, F. Larribe, Water, Air, and Soil Pollution 97, 31 (1997)

20. B.R. Forsberg, M.C.S. Forsberg, C.R. Padovani, E. Sargentini, O. Malm, Proceedings of the Intenrational Workshop on Environmental Merucry Pollution and Its Health Effects in the Amazon River Basin, National Institute for Minamata Disease, Rio de Janeiro, 33-40 (1995)

21. M. Roulet, M. Lucotte, R. Canuel, I. Rheault, S. Trans, Y.D.F. Gog, N. Farella, D. Megler, M. Amorim, Proceedings of the Fourth International Symposium on the Geochemistry of the Earth's Surface: Short Papers, IIkley, Yorkshire, England, n.d., 453-457

22. M. Roulet, M. Lucotte, R. Canuel, I. Rheault, S. Trans, N. Farell, R.S.D. Vale, C.S. Passos, E.D.J.D. Silva, Science of The Total Environment 213, 203 (1998)

23. P.J. Lechler, J.R. Miller, L.D. Lacerda, D. Vinson, J.C. Bonzongo, W.B. Lyons, J.J. Warwick, Science of the Total Environment 260, 87 (2000) 
24. M.G. Mackin, Floodplain Processes, edited by M.G. Anderson, D.E. Walling, P.D. Bates, John Wiley \& Sons, Ltd, 441-460 (1996)

25. M.G. Macklin, P.A. Brewer, K.A. Hudson-Edwards, G. Bird, T.J. Coulthard, I.A. Dennis, P.J. Lechler, J.R. Miller, J.N. Turner, Geomorphology 79, 423 (2006)

26. T.M. Grygar, J. Popelka, Journal of Geochemical Exploration 170, 39 (2016)

27. S. Stokes, D.E. Walling, Tools in Fluvial Geomorphology, John Wiley \& Sons, Ltd, 231-267 (2005)

28. M.G. Macklin, K. Klimek, Applied Geography 12, 7 (1992)

29. K. Hudson-Edwards, M. Macklin, M. Taylor, Science of The Total Environment 194-195, 437 (1997)

30. G. Tobin, R. Brinkmann, B. Montz, Flooding and the Distribution of Selected Metals in Floodplain Sediments in St. Maries, Idaho (2000)

31. P. Pease, S. Lecce, P. Gares, C. Rigsby, Environmental Geology 51, 1103 (2007)

32. G. Du Laing, J. Rinklebe, B. Vandecasteele, E. Meers, F.M.G. Tack, Science of The Total Environment 407, 3972 (2009)

33. T. Matys Grygar, I. Světlík, L. Lisá, L. Koptíková, A. Bajer, D.S. Wray, V. Ettler, M. Mihaljevič, T. Nováková, M. Koubová, J. Novák, Z. Máčka, M. Smetana, CATENA 80, 106 (2010)

34. T. Matys Grygar, T. Novakova, O. Bábek, J. Elznicova, N. Vadinová, Robust Assessment of Moderate Heavy Metal Contamination Levels in Floodplain Sediments: A Case Study on the Jizera River, Czech Republic (2013)

35. E. Ferrand, F. Eyrolle, O. Radakovitch, M. Provansal, S. Dufour, C. Vella, G. Raccasi, R. Gurriaran, Geochimica et Cosmochimica Acta 82, 163 (2012)

36. National Academies of Sciences Engineering and Medicine, Investigative Strategies for Lead-Source Attribution at Superfund Sites Associated with Mining Activities, The National Academies Press, Washington, DC (2017)

37. J.R. Miller, G. Mackin, S.M. Orbock Miller, Application of Geochemical Tracers to Fluvial Sediments, Springer, Heidelberg (2015)

38. Integral, Sources of Lead to Residential Soils of St. Francois County, Integral Consulting, Inc., Missouri, (2014)

39. R.J. Miller, D. Walsh, F.L. Villarroel, Geosciences 9, (2019)

40. A.J. Horowitz, Primer on Sediment-Trace Element Chemistry, Lewis Publishers (1991)

41. S. Covelli, G. Fontolan, Environmental Geology 30, 34 (1997)

42. M.G. Vijver, J. Spijker, J.P.M. Vink, L. Posthuma, Environmental Pollution 156, 832 (2008)

43. T. Matys Grygar, J. Elznicová, O. Bábek, M. Hošek, Z. Engel, T. Kiss, Applied Geochemistry 48, 1 (2014)

44. S. Sakan, N. Sakan, D. \DJorld jević, Advances in Chemistry Research 167 (2015)

45. G. Weltje, Sedimnetary Geology 280, 4 (2012)

46. Y.S. Zhang, A.L. Collins, A.J. Horowitz, Hydrological Processes 26, 326 (2012)
47. K. D'Haen, G. Verstraeten, P. Degryse, Progress in Physical Geography 36, 154 (2012)

48. S.E. Church, D.M. Unruh, D.L. Fey, T.C. Sole, Trace Element and Lead Isotopes in Streambed Sediments Affected by Historical Mining, U.S. Geological Survey, Washington D.C. (2004)

49. J.R. Miller, G. Mackin, Water, Air, \& Soil Pollution 224, 1613 (2013)

50. G. Bird, Environment International 37, 802 (2011)

51. Y. Erel, A. Veron, L. Halicz, Geochimica et Cosmochimica Acta 61, 4495 (1997)

52. J.R. Miller, P.J. Lechler, G. Mackin, D. Germanoski, L.F. Villarroel, Science of The Total Environment 384, 355 (2007)

53. F. Monna, J. Lancelot, I.W. Crowdace, A.B. Cundy, J.T. Lewis, Environmental Science \& Technology 31, 2277 (1997)

54. G. Bird, P.A. Brewer, M.G. Macklin, M. Nikolova, T. Kotsev, M. Mollov, C. Swain, Environmental Pollution 158, 2158 (2010)

55. T.J. Shepherd, S.R.N. Chenery, V. Pashley, R.A. Lord, L.E. Ander, N. Breward, S.F. Hobbs, M. Horstwood, B.A. Klinck, F. Worrall, Science of The Total Environment 407, 4882 (2009)

56. T. Bullen, Stable Metal Isotope Fractionation Processes and Applications in Environmental Geochemistry, Ascona Switzerland (2103)

57. A. Stenberg, H. Andrén, D. Malinovsky, E. Engström, I. Rodushkin, D.C. Baxter, Anal. Chem. 76, 3971 (2004)

58. D.J. Weiss, T.F.D. Mason, F.J. Zhao, G.J.D. Kirk, B.J. Coles, M.S.A. Horstwood, New Phytologist 165, 703 (2005)

59. I. Rodushkin, A. Stenberg, H. Andrén, D. Malinovsky, D.C. Baxter, Anal. Chem. 76, 2148 (2004)

60. O.S. Pokrovsky, J. Viers, E.E. Emnova, E.I. Kompantseva, R. Freydier, Geochimica et Cosmochimica Acta 72, 1742 (2008)

61. T.F.D. Mason, D.J. Weiss, J.B. Chapman, J.J. Wilkinson, S.G. Tessalina, B. Spiro, M.S.A. Horstwood, J. Spratt, B.J. Coles, Chemical Geology 221, 170 (2005)

62. J.J. Wilkinson, D.J. Weiss, T.F.D. Mason, B.J. Coles, Economic Geology 100, 583 (2005)

63. C. Cloquet, J. Carignan, M.F. Lehmann, F. Vanhaecke, Analytical and Bioanalytical Chemistry 390, 451 (2008)

64. Y. Sivry, J. Riotte, J.E. Sonke, S. Audry, J. Schäfer, J. Viers, G. Blanc, R. Freydier, B. Dupré, Chemical Geology 255, 295 (2008)

65. Y. Chen, L. Yuan, C. Xu, Environ Earth Sci 76, 226 (2017) 